\title{
Apresentação do dossiê Comunicação e Historicidades
}

\author{
Eduardo Victorio Morettin' \\ https://orcid.org/0000-0002-1207-4969 \\ I - ECA/USP \\ São Paulo (SP), Brasil
}

O dossiê Comunicação e Historicidades divulga os resultados dos trabalhos desenvolvidos pelos integrantes da rede Historicidades dos Processos Comunicacionais, nascida em 2015, em Belo Horizonte, a partir da reunião de grupos de pesquisa dedicados ao estudo do tempo como categoria para compreensão dos fenômenos e produtos da comunicação ${ }^{1}$. Integram a rede os seguintes grupos de pesquisa: Tramas Comunicacionais (UFMG), Historicidades das formas comunicacionais (UFMG), Centro de Pesquisa em Estudos Culturais e Transformações na Comunicação (UFBA), Cultura Audiovisual, Historicidades e Sensibilidades (UFBA), Núcleo de Estudos em Comunicação, História e Saúde (Fiocruz), Grupo de Estudos em Experiência Estética: Comunicação e Artes (UFRB), Grupo de Pesquisa em Mídia e Interações Sociais (UFOP), Núcleo de Pesquisa em Jornalismo e Comunicação (UFPI), Núcleo de Estudos e Projetos em Comunicação (UFRJ), Grupo de Pesquisa e Extensão Telejornalismo, Narrativas e Sociedade (UFRB) e História e Audiovisual: circularidades e formas de comunicação (USP).

Desde de sua criação, a rede Historicidades dos Processos Comunicacionais promove dois encontros por ano em universidades que abrigam os programas de pós-graduação em Comunicação aos quais os grupos de pesquisa estão vinculados. A partir de um recorte temático previamente discutido, pesquisadores em momentos de formação distintos (docentes, pós-doutorandos, doutorandos e mestrandos) discutem as formulações teóricas concernentes aos regimes de historicidades, refletindo também sobre a sua especificidade pensada em fenômenos, mídias e processos singulares. No primeiro encontro do ano, os participantes são instigados a apresentar as ideias norteadoras de cada proposta. No segundo, os artigos completos gerados a partir desta reunião são debatidos. Tal foi o percurso observado na sétima edição do encontro, realizada em junho de 2018 na UFMG, e na oitava, ocorrida na UFBA em outubro do mesmo ano.

Os artigos que compõem o dossiê Comunicação e Historicidades participaram deste processo, que foi finalizado com o encaminhamento à Galáxia de uma proposta de dossiê, aceita pelo seu conselho editorial, e com a publicação dos papers selecionados a partir

1 Para maiores informações sobre a rede de grupos de pesquisa ver https://encontrohistoricidades.wordpress.com/ blog/, acesso em 22/07/2019. 
da avaliação realizada pelos pareceristas de seu conselho científico.

Os artigos abordam, em linhas gerais, os movimentos epistêmicos, políticos, estéticos e culturais de nosso tempo, marcado, como sabemos, pelo combate ao conhecimento e suas formas de manifestação. Neste sentido, nada mais oportuno do que refletir sobre as relações entre Comunicação e Historicidade, pensadas em seus momentos e espaços históricos específicos e levando-se em consideração a dimensão processual, os movimentos de ruptura e continuidade e as múltiplas temporalidades implicadas, em esforço de apreender os processos de contextualização que dialeticamente interagem com os fenômenos comunicacionais.

A dimensão teórica e conceitual marca os dois artigos que abrem o dossiê Comunicação e Historicidades. Itania Gomes e Elton Nunes, em Repensar a comunicação com Raymond Williams: estrutura de sentimento, tecnocultura e paisagens afetivas, refletem sobre "a importância da hipótese cultural de estrutura de sentimento, de Raymond Williams, para as discussões e análises que tomam a noção de historicidade como decisiva para as reflexões em torno das práticas comunicativas e culturais", valorizando-se a compreensão dos "engajamentos identitários, em articulação com paisagens afetivas, aspectos decisivos para se pensar o contemporâneo". Bruno Leal e Igor Sacramento, em A tradição como problema nos estudos de comunicação: reflexões a partir de Williams e Ricoeur, retomam Williams para, junto com Paul Ricoeur, pensar "a dimensão interpretativa e os complexos movimentos temporais presentes na tradição". Reconhecendo a diversidade entre os dois autores, o movimento é o de "mostrar como ambos, a seu modo, entendem a tradição como algo instável, imersa em conflitos epistêmicos, éticos e ideológicos e encontram, na disputa sobre o passado, a configuração do presente e a projeção de futuros".

Há um conjunto de artigos dentro do dossiê voltado à discussão da historicidade a partir de fenômenos, mídias e processos singulares, como já apontei acima. Nuno Manna e Igor Lage, em Uma "catástrofe do tempo": narrativa e historicidade pelas 'Vozes de Tchernóbil', analisa a forma como o livro Vozes de Tchernóbil (1997), de Svetlana Aleksiévitch, registra ficcionalmente a dimensão temporal de um evento traumático, a saber, o desastre nuclear ocorrido na antiga União Soviética, mobilizando testemunhas e a própria experiência da autora. Já Descarga acústico-visual e temporalidades em cena: a fundação de uma tradição pela Banda Calypso, de Phellipy Jácome, Denise Prado e Rafael Azevedo, se volta ao estudo de certa tradição de música popular fundada pela Banda Calypso, tendo como objeto o DVD comemorativo dos 15 anos do grupo paraense, suporte que permite a incursão, dentre outros aspectos, nas estratégias visuais e sonoras para a construção de matrizes temporais que procuram justificar o lugar auto-atribuído pelo conjunto musical. O universo audiovisual continua em pauta no artigo Os tempos no Paraguaçu: juventude, mediações culturais e YouTube, de Daniela Matos, Jussara Maia e Valéria Vilas Bôas, que se ocupa das produções audiovisuais do coletivo Equipe Iskálifá, formado por jovens moradores de São Félix (BA), com o objetivo de, ao configurar as diferentes temporalidades destes materiais, "evidenciar o duplo esforço implicado, de produção de material audiovisual e de sujeitos produtores que revelam movimentos do tempo transpassados por valores, sentidos e práticas hegemônicas, alternativas e oposicionais". OYouTube é objeto também de Gênero midiático, performance e corpos em trânsito: uma análise sobre dissidências da conversação televisiva em canais no YouTube, de Juliana Gutmann, Edinaldo Mota Junior e Fernanda Mauricio da Silva. 
Os autores estudam as "transformações da conversação televisiva operadas no YouTube, com especial interesse em corpos que se posicionam como dissidentes" a partir de três canais - Põe na Roda, Canal das Bee e Drag-se. A série de televisão The Handmaid's tale é examinada por Felipe Borges e Isabelle Chagas em 'A men's place': o passado como referência para o futuro das masculinidades em 'The Handmaid's tale'. Interessa aos autores pensar as articulações entre a forma como se articulam utopia, distopia e retrotopia na "busca pela reafirmação de um ideal de masculinidade que dá o tom do regime autoritário, no qual os homens estabelecem o poder a partir da subjugação da mulher, do enrijecimento do conceito de família e do controle do espaço".

O dossiê se encerra com dois artigos que nos convocam a refletir sobre o dissenso e as maneiras de enfrentá-lo. Carlos Alberto Carvalho e Gislene Fonseca, em Violência em acontecimentos políticos: jornalismo e lawfare no caso Lula, "examinam as ações que levaram à condenação, à prisão e ao impedimento da candidatura à presidência em 2018 do expresidente Luiz Inácio Lula da Silva, tomando como referência o conceito de acontecimento entendido como violência, bem como as dimensões de violência na política". Por fim, Márcio Gonçalves e Paulo Bernardo Vaz, em Comunicação e tempo: reflexões em favor das diferenças, propõem a reflexão teórica entre tempo e comunicação e seus paradigmas para então avaliar a premente questão da diferença no Brasil contemporâneo.

Desejo que o leitor compartilhe o esforço aqui apresentado não apenas de contribuir para o adensamento conceitual das historicidades dos processos comunicacionais, mas de refletir sobre sua importância para entendermos e enfrentarmos os desafios que se colocam em nosso horizonte.

Boa leitura!

Dossiê 'Movimentos do tempo: política, cultura e mídia'. Revista Contracampo, 2018, v. 37, n. 3: [Acesso em: 7 de agosto de 2019] Disponível em: <http://periodicos.uff.br/contracampo/issue/view/1478>

LEAL, B,; SACRAMENTO, I.; GOMES, I. Do contexto à contextualização: dinâmicas das historicidades dos processos comunicacionais - Apresentação do Dossiê. Revista FAMECOS: mídia, cultura e tecnologia. 2017, 24 (Setembro-Dezembro) : [Acesso em: 7 de agosto de 2019] Disponível em: <http://www.redalyc.org/articulo.oa?id=495553932010>

RÊGO, A. R., HOHLFEDLT, A.; MACHADO, B. (orgs.). Os desafios da pesquisa em história da comunicação: entre a historicidade e as lacunas da historiografia. Porto Alegre: Ed. PUC-RS, 2019.

RIBEIRO, A. P. G.; LEAL, B.; GOMES, It. As historicidades dos processos comunicacionais: elementos para uma abordagem. In: MUSSE, C. F.; VARGAS, H.; NICOLAU, M. (orgs.). Comunicação, mídias e temporalidade. Salvador: Edufba, 2017, p. 37-58.

Eduardo Victorio Morettin é professor da Escola de Comunicações e Artes da Universidade de São Paulo e autor de Humberto Mauro, Cinema, História (São Paulo, Alameda Editorial. É bolsista Produtividade em Pesquisa CNPq.

cunhamorettin@uol.com.br 